This is an electronic reprint of the original article. This reprint may differ from the original in pagination and typographic detail.

Author(s): Nylen, Aletta; Isomöttönen, Ville; Daniels, Mats; McDermott, Roger

Title: $\quad$ Open-Ended Projects Opened Up : Aspects of Openness

Year: $\quad 2017$

Version:

Please cite the original version:

Nylen, A., Isomöttönen, V., Daniels, M., \& McDermott, R. (2017). Open-Ended Projects Opened Up : Aspects of Openness. In FIE 2017 : IEEE Frontiers in Education Conference 2017 (pp. 1-7). IEEE. Conference proceedings : Frontiers in Education Conference. https://doi.org/10.1109/FIE.2017.8190510

All material supplied via JYX is protected by copyright and other intellectual property rights, and duplication or sale of all or part of any of the repository collections is not permitted, except that material may be duplicated by you for your research use or educational purposes in electronic or print form. You must obtain permission for any other use. Electronic or print copies may not be offered, whether for sale or otherwise to anyone who is not an authorised user. 


\section{Open-Ended Projects Opened Up - Aspects of Openness}

\author{
Aletta Nylén, Mats Daniels \\ Dept. of Information Technology \\ Uppsala University \\ Uppsala, Sweden \\ aletta.nylen@it.uu.se \\ mats.daniels@it.uu.se
}

\author{
Ville Isomöttönen \\ Dept. of Mathematical Information \\ Technology \\ University of Jyväskylä \\ Jyväskylä, Finland \\ ville.isomottonen@jyu.fi
}

\author{
Roger McDermott \\ School of Computer Science and \\ Digital Media \\ Robert Gordon University \\ Aberdeen, United Kingdom \\ roger.mcdermott@rgu.ac.uk
}

\begin{abstract}
One of the most important areas of competence for professional engineers is the ability to function well in project work, in particular they need to be able to efficiently solve open-ended problems in different collaborative settings. The development of this ability is however not prominent in engineering education despite numerous authors suggesting openended problems as a pedagogical tool to promote development of collaborative problem solving competence by including elements of group or project work in courses. In our own long experience of using open-ended problems in collaborative student projects, we have identified a lack of systematic progression in learning outcomes and skill development. We see this as a major obstacle for fully exploiting the potentials of using open-ended problems as an educational tool. We present a framework that provides a structured view of challenges related to openness that students can encounter in educational projects and that has an impact on the overall complexity of the project. We argue that there are different categories of openness to consider when designing educational settings based on open-ended projects. The categories addressed in this paper are: Character of the problems addressed. Character of the teams. Time constraints. Faculty involvement. External factors. Aspects of openness in the different categories are presented and related to professional engineering competencies. Furthermore, it is discussed how variations in project complexity can be accomplished by variations within the aspects and combinations of aspects. In particular, the framework addresses development and progression of professional competencies.
\end{abstract}

Keywords - engineering education; project work; progression; professional competencies; open-ended problems

\section{INTRODUCTION}

It is often stated that professional competencies are important in workplaces, e.g. OECD [1], ACM [2], US National Academy [3], Danish Engineers union [4], and IEEE [5], and educational degree programs typically include as overarching goals that the graduates have developed a variety of such competencies. One of the most important areas of competence for professional engineers is the ability to function well in project work, in particular they need to be able to efficiently solve open-ended problems in different collaborative settings [6].

There is however, a gap between these rather abstract, highlevel goals and what actually happens in the courses comprising typical engineering degree programs. Examples of this gap is that it is rare that course descriptions contain professional competencies as learning outcomes, and in those that do, this aspect is often marginalised [7]. Another example is the experience as an evaluator in the recent Swedish evaluation of Computer Science and IT degree programs, where learning objectives of professional competencies type were considered, but with a low bar regarding what was considered 'good enough'.

A number of pedagogical approaches that attempt to bridge this gap have been proposed, e.g., collaborative learning [8], team based learning [9], problem- and project-based learning [10], open-ended problem solving [6], open-ended group projects [11]. Reports from using such approaches typically convey increased student motivation and enhanced learning regarding both content knowledge and competence development. Despite this work and these positive reports we argue that there is a resistance to using these approaches stemming from a general insecurity about the meaning of professional competencies and how to assess students. This can for instance be illustrated by Durn and Amandis [12] observation about collaborative skills development in the context of collaborative learning:

not all the students develop the same collaborative skills ... and not all the students develop the skills at the same level.

Another obstacle might be that most of these approaches use a constructivist approach to instruction, where students are faced with openness and teachers are primarily seen as facilitators that provide minimal guidance. Kirschner et. al [13] argues against using minimal guidance approaches as pedagogical tools. They argue that, with minimal guidance, students need to construct knowledge of procedures as well as content simultaneously, which causes a cognitive load that is beyond their capability. However, we believe that systematic progression in the degree of openness throughout a degree program will allow students to achieve the procedural and content knowledge and experiences needed to be capable of coping with more openness towards the end of the education. Furthermore, knowledge of such procedures and ability to properly apply them, i.e., having professional competencies, are essential learning objectives in degree programs.

We see an understanding of the concept of openness as 
a key issue for improving degree programs regarding development of professional competencies. In this paper we will exemplify capturing the progression aspect with the use of course specifications, something that previously, according to anecdotal evidence, have had limited success. The reasons voiced have mostly been about faculty feeling insecure about what the professional competencies in question actually mean and how to assess if (individual) students have acquired them. Of equal, or perhaps even greater, importance is to convey an understanding regarding openness to the student cohort. We see projects as an excellent base for educational settings aimed at developing professional competencies and will give a special focus on pedagogical approaches using projects.

We will in this paper present a framework for reasoning about aspects of openness when designing educational settings based on projects. This framework provides a structured view of challenges related to openness that students can encounter in educational projects, and can thus support specification of progression. The structure is in the form of categories of openness and aspects of these categories are discussed in terms of learning goals regarding professional competencies. The categories addressed in this paper are: 1) Character of the problems addressed, 2) Character of the teams, 3) Time constraints, 4) Faculty involvement, and 5) External factors.

We will first provide an overview of project-based education and competencies needed for engineers in the future as background for our proposal. Then we present our proposed framework for openness, where we describe different aspects of the categories we identified. One way to use the framework is to support definition of progression of professional competencies and we discuss this in general and give a concrete example from an IT engineering degree program. The value of this and other uses of the framework, e.g. assisting assessment, as well as future work are discussed in the conclusion.

\section{TAxonomic Studies on Projeect-Based EDUCATION}

Project-based education has been categorized by many scholars. Shaw and Tomayko [14] classifies undergraduate software engineering courses based on the amount of project work included. They criticize almost fully lectured 'project courses' where praxis is missing or occur only in the form of student presentations. 'Small group projects' instead use half of the course time on lectures and the other half on a project, with the first half granting opportunities to initiate students' knowledge and skills for the project. On the grounds that authentic praxis is the best way to immerse students to software engineering, Shaw and Tomayko prefer 'Large group projects' where students are given a few lectures but mostly work on the project and often for external clients. In this setting, the students work in a large group and are assigned to authentic software engineering roles. Finally, the 'Project only' represents a course implementation with no lectured content included. Knoke [15] extends the model by adding a 'Medium size project model'where small teams implement a realistic project during one semester. A team functions as a software development company and develops a software product for a customer, and is required to document many parts of the project.

Computer science project work has later been categorized by Fincher et al. [16] and Clear et al. [17]. Fincher et al. presented eleven forms of projects based on actual practice at over 50 institutions. These included integrative projects, design and build-projects, projects emphasizing process instead of a product, projects with industry involvement or for real clients, potentially competitive projects where students hand over their components to be integrated into a larger system, final-year individual projects, research-like projects, and so forth. Clear et al. instead reviewed a wide range of course attributes to build a resource for teachers setting out to devise a project course. Their considerations included questions such as what are the goals of the course, who conceives the projects, what documentation is produced, what is archived, what work process is followed, how projects are presented, can NonDiscloser Agreements be included, and how team/sponsor conflicts are addressed. Both Fincher et al. [16] and Clear et al. [17] argued that "function drives that form" [17], that is, when the learning goals of the project course are identified, it is possible to select course attributes according to that goal.

At the same time, Bothe [18] proposed a categorization on the degree of realism in projects. The realism in this taxonomy signified that the project's requirements source is based on a real demand instead of an academic one, real-life application domains are used instead of typical system programs, commercial customers are involved instead of having a lecturer as a customer, product versions are preferred over prototypes, high priority is sought for in place of low priority, deadlines are preferred over no deadlines, large scale projects are commenced instead of small ones, all life-cycle phases are included instead of selected phases, and reverse engineering is preferred over mere maintenance. Bothe specifically noted that from-scratch projects are problematic if high-priority real-customer projects are sought for. He preferred reverse engineering projects for promoting realistic experience and generally raised the challenge with deadlines in educational settings.

Later, Burge and Gannod [19] presented dimensions for categorizing capstone projects. They concentrated on project type, customer identity, user identity, audiences of project work and the deliverables required by the differing audiences, availability of original developers (in case of continued work), and the number of teams working on a single project. Burge and Gannod preferred from-scratch projects because, they argued, such projects usefully expose students to ill-formed situation in terms of requirements elicitation. The authors also argued that multiple teams working on the same problem is not as realistic as having single team fully responsible for the project.

A taxonomic mark is also present in literature reviews. An already dated review by Todd et al. [20] in the North American context revealed, for instance, that one semester was the most common timescale for a project $(45 \%), 83 \%$ of capstones were 
located in the single department, a small team was the most common team size (1-3 students: $38 \%$ and 4-6 students: $49 \%$ ), in $18 \%$ of projects with external funding, the customer directed a payment to the university, and over half of the projects $(59 \%)$ were received from the department and roughly the same number $(58 \%)$ originated from external parties, meaning that often both sources were used. Richards [21] reviewed literature to inform design choices in particular regarding group formation and assessment. One of her key conclusions was the importance of fairness within student teams and the call for interventions were the contributions of group members are addressed through self- and peer assessment.

Today, project-based learning has extended to multicultural [22] and multi-disciplinary projects [23]. Furthermore, some scholars have specifically emphasized use of open-ended problems in projects, which indicates no inevitable direction or means for students' problem solving [24]. Such problem solving emphasizes 'divergent' thinking over 'convergent' thinking and links with creativity due to increased flexibility and originality [25]. The studies above do not specifically address the use of open-ended problems in projects and effective dimensions therein. The present study complements the taxonomic literature from this perspective.

\section{Professional Competencies for EngineERS}

We have already established that development of professional competencies is regarded as important in engineering education. The work by Pellegrino \& Hilton [3] that investigated what competencies are needed for future professionals, which they refer to as 21 st century competencies (Table I), is a good example for representing arguments for the importance.

We view 21 st century skills as knowledge that can be transferred or applied in new situations. This transferable knowledge includes both content knowledge in a domain and also procedural knowledge of how, why, and when to apply this knowledge to answer questions and solve problems. The latter dimensions of transferable knowledge (how, why, and when to apply content knowledge) are often called "skills." We refer to this blend of content knowledge and related skills as "21st century competencies." [3]

Their findings are well aligned with the competencies often mentioned as learning goals in engineering education. In the report, competencies are classified based on their domain of operation, cognitive, interpersonal and intrapersonal, see Table I. The work points out that the domains are differentiated for purposes of understanding and organising competencies, but that they are intertwined in human development and learning.

We argue that most, if not all, of the content in Table I require an ability to deal with openness, which aligns well with the concept of open-ended problems in educational settings. As we see it, the aim of open projects in education is not only to develop students behaviors in project work (mainly inter- and intrapersonal), but also to promote development in all of these domains, including learning content knowledge. However, in
TABLE I

21ST CENTURY COMPETENCIES

\begin{tabular}{|c|c|c|}
\hline Main category & Subcategories & Terms used \\
\hline \multirow[t]{3}{*}{$\begin{array}{l}\text { Cognitive } \\
\text { Competencies }\end{array}$} & $\begin{array}{l}\text { Cognitive Processes } \\
\text { and Strategies }\end{array}$ & $\begin{array}{l}\text { critical thinking, problem solv- } \\
\text { ing, analysis, reasoning/ argu- } \\
\text { mentation, interpretation, deci- } \\
\text { sion making, adoptive learn- } \\
\text { ing, executive function }\end{array}$ \\
\hline & Knowledge & $\begin{array}{l}\text { information literacy, ICT, oral } \\
\text { and written communication, } \\
\text { active listening }\end{array}$ \\
\hline & Creativity & creativity, innovation \\
\hline \multirow[t]{3}{*}{$\begin{array}{l}\text { Intrapersonal } \\
\text { Competencies }\end{array}$} & $\begin{array}{l}\text { Intellectual } \\
\text { Openness }\end{array}$ & $\begin{array}{l}\text { flexibility, adaptability, artistic } \\
\text { and cultural appreciation, per- } \\
\text { sonal and social responsibility, } \\
\text { cultural awareness and compe- } \\
\text { tence, appreciation for diver- } \\
\text { sity, continuous learning, intel- } \\
\text { lectual interest and curiosity }\end{array}$ \\
\hline & $\begin{array}{l}\text { Work Ethic / Consci- } \\
\text { entiousness }\end{array}$ & $\begin{array}{l}\text { initiative, self-direction, } \\
\text { responsibility, perseverance, } \\
\text { productivity, grit, } \\
\text { metacognitive skills including } \\
\text { forethought, performance, and } \\
\text { self-reflection }\end{array}$ \\
\hline & $\begin{array}{l}\text { Positive Core Self- } \\
\text { Evaluation }\end{array}$ & $\begin{array}{l}\text { self-monitoring, self- } \\
\text { evaluation, self-reinforcement, } \\
\text { physical and psychological } \\
\text { health }\end{array}$ \\
\hline \multirow[t]{2}{*}{$\begin{array}{l}\text { Interpersonal } \\
\text { Competencies }\end{array}$} & $\begin{array}{l}\text { Teamwork and col- } \\
\text { laboration }\end{array}$ & $\begin{array}{l}\text { communication, collaboration, } \\
\text { teamwork, cooperation, coor- } \\
\text { dination, interpersonal skills, } \\
\text { empathy/ perspective taking, } \\
\text { trust, service orientation, con- } \\
\text { flict resolution, negotiation }\end{array}$ \\
\hline & Leadership & $\begin{array}{l}\text { leadership, responsibility, as- } \\
\text { sertive communication, self- } \\
\text { presentation, social influence } \\
\text { with others }\end{array}$ \\
\hline
\end{tabular}

this work the focus is mainly on developing competencies in all three domains that are directly related to students' ability to be efficient and productive workers and learners in projects.

\section{Aspects OF OPENNESS IN EDUCATION}

Discussions with students and written reflections on the subject of openness at the end of a semester long openended international project course indicate that most of these master level students have rarely encountered openness in their education and that they felt ill-prepared for dealing with a project that was open-ended in many aspects. They actually had difficulties in expressing and came up with varied aspects of what they considered open-endedness to be about. This is probably an effect of the complexity of the openness concept, where complexity actually could be considered as a common aspect of openness. It was also clear from the above mentioned discussions and written reflections that most students saw openness after the initial 'deciding what to do phase' as problematic and unwanted, they often saw the time to decide as wasteful. It is the authors' impression that dealing with 
different aspects of openness was seen as important learning goals, but yet also something that could be done faster and/or with more support from faculty. Arguing for openness as a means towards learning professional competencies has been important for motivating students, but more can be done in that regard and this work is a step towards providing support for faculty and students.

The example above illustrates that openness in education can have many facets. We think of aspects of openness as aspects adding to the complexity of a project by facing students with choices. The choices can be of different kinds and magnitudes, ranging from deciding what the assignment is about, what product to produce, to deciding frequency and times for group meetings and distributing work within the team.

We present a framework for aspects of openness in education, mainly in the form of student projects, consisting of five main categories. A number of aspects within each category are presented and discussed. The focus will be on making a connection to implementation in educational settings. Issues, such as progression and connection to the categories of professional competencies given in the section above, will mostly be done in the two following sections.

1) Character of the problems addressed

2) Character of the teams

3) Time constraints

4) Faculty involvement

5) External factors

\section{A. Character of the Problems Addressed}

The character of a problem can have a quite varied effect on the openness of the learning experience. A not uncommon variant is that there is an initial phase when there is an openness in terms of deciding what the problem is all about, but once that is decided the problem has transformed into a fixed, and from the students view, safe, assignment. For instance, when students develop software based on their own ideation of project topics and software products therein, there is a tendency that students refrain from further ideation as soon as they have selected the topic and made the design for the first prototype. This indicates a willing transfer from an open-ended situation to a safe place that resembles faculty given problems. Building software necessitates understandings of main use cases and design early on, which grants such opportunities for transforming the situation early on. On the other hand, this transfer is also the aim of the students' work: students must be able to advance their project from an initially open-ended and ill-formed situation. Here, we are nevertheless pointing out the tendency to seek for and remain in the safe place instead of continuing to capitalize on the 'creativity supporting learning environment' - a term used by Apiola et al. [26]. Anecdotal evidence suggests that it is easier for students to delay transfer to a fixed, safe, assignment if assessment is more focused on process and less on product.

There are normally many acceptable solutions to a problem. The extreme point is to have only one, which is something most students are most used to. The advantage with problems with only one solution is that faculty can control what the students do. Such problems are however almost non-existent when the complexity of the problem is increased. Problems with many acceptable solutions can, as described above, be turned into problems with few or only one acceptable solution in the process of dealing with them. The educational setting could, as opposed to the scenario above, be faculty controlled by requiring the students to make a choice about which solution to aim for. The acceptable solutions in an educational setting can also be related to grades, e.g. by requiring an implementation for a higher grade. Problems could also have an internal complexity that defies transformation into safe 'one right answer' problems.

Problems could be such that they are based on knowledge the students already are assumed to possess or to be such that the students are expected to acquire new knowledge. The level of openness can be varied even further by more or less strict restrictions on what knowledge students are to acquire in order to fulfill course learning outcomes.

Thus we have identified the following aspects to be relevant in discussing openness with regard to the character of the problem to address:

- Acceptable solutions - the more acceptable solutions the higher the openness.

- Complexity - higher complexity yield higher openness.

- Knowledge requirements - requiring gaining new knowledge generally means higher openness.

- Problem solving methods - a larger set of potential methods leads to higher openness.

- Process vs product focus - a product focus can lead to a lesser level of openness.

\section{B. Character of the Teams}

The character of the teams working in a project can be designed in many different ways. The perhaps most obvious is to vary the number of members in a team. With increased number of members aspects such as heterogeneity of the team and project organisation can be addressed. The heterogeneity aspect can be about gender, culture, and expertise. The expertise aspect can be to let students at different levels in the same degree program collaborate, but other examples are mixing students from different disciplines and/or involving users.

The character of a team is also about how the work is organised. Variations here are for instance how free the students are to choose how they want to collaborate and which tools to use. Other examples regarding organisation are having roles rotating within a team and/or moving students between different teams.

Thus we have identified the following aspects to be relevant in discussing openness with regard to the character of the teams:

- Group size - larger group size generally leads to higher openness.

- Heterogeneousness - the more heterogeneous a team is the higher the openness is. 
- Project organization - the more freedom regarding how to organise the higher openness.

\section{Time Constraints}

Time constraints, such as deadlines, can have a major effect on the openness of an educational setting. For instance, having many and detailed deadlines will restrict the openness considerably. The major deadline is of course the end of the course, which is especially important to relate to when external clients are involved.

Another type of time constraint stems from a combination of factors within and outside the particular educational setting. This is about how students optimize their time, e.g. with regard to the learning resources in the degree program. An example of that is, when students observe a sufficient degree of completion in their learning assignment, they might target their resources elsewhere. This may constrain the amount of explorative learning (e.g., reliance on creativity and divergent thinking) that is expected to occur in an open-ended setting.

Time constraints can also be in the form of members residing in different time zones. This typically occurs in international collaborations, where an additional constraint typically occurs in the form of the respective courses having different starting and/or ending dates.

Thus we have identified the following aspects to be relevant in discussing openness with regard to time constraints:

- Limited time for the project - less time leads to lower level of openness.

- Teams being distributed over different time zones greater difference leads to higher level of openness.

- Members having non-equal amount of time to spend on the collaboration - greater difference leads to higher level of openness.

- Members having other engagements to different degrees more other engagements lead to higher level of openness.

\section{Faculty Involvement}

Faculty involvement is perhaps the major contributor to the openness of an educational setting. Even the most complex setting can have a pretty low level of openness if the faculty involvement is high. Examples of aspects to consider with regard to faculty involvement are amount and type of scaffolding, that is to decide which type of guiding role faculty will take. Related to this is also the issue of when scaffolding should be offered, e.g. detailed deadlines is an example of a technique for providing scaffolding. The timing of scaffolding can also be derived from faculty observations or initiated from the student cohort.

It is also possible to correspond with students regularly without imposing high faculty involvement. One way is to have regular (e.g., on weekly basis) dialogic sessions (the type of scaffolding) with student groups regardless of the potential need for help on the part of students. Such sessions can be very short (e.g., 15 minutes) or long (e.g., two hours) in duration. The goal is to develop an informal setting between the faculty and students, and hence facilitate help-seeking behaviors across a range of learners and learner groups. Such flexibility means that the timing and amount of scaffolding still follows the needs expressed by the students and is not imposed. This regularity, being a part of the course arrangements, also means that the initiation of the scaffolding is, in a way, managed by the faculty, while the flexibility of the sessions indicates that the contents of the sessions are much drawing on the students' initiative.

Thus we have identified and illustrated the following aspects to be relevant in discussing openness with regard to faculty involvement:

- Amount of scaffolding - more leads to lower level of openness.

- Type of scaffolding - all forms lead to lower level of openness.

- Timing of scaffolding - the earlier the lower level of openness.

- Initiation of involvement - faculty initiated lead to lower level of openness.

It should be noted that faculty involvement is more or less unavoidable and how much the openness is affected is highly dependent on what the actual involvement is.

\section{E. External Factors}

Some aspects that can be seen as being related to external factors have already be introduced, e.g. students having demands outside the project and international collaborations being influenced by different start/end dates and different sets of public holidays. Other aspects relate to having external stakeholders, e.g., a client ordering the project, external members in teams, and users.

Elements of engagement with authentic environments, e.g., equipment not specifically adjusted for the learning environment or people not connected to the course, adds complexity and unpredictability for both students and teachers. External factors can also be more abstract, as in society in general. Thus we have identified the following aspects to be relevant in discussing openness with regard to external factors:

- Having external stakeholders - having them increases the level of openness.

- Having external members in teams - having them increases the level of openness.

- Engaging with authentic environments - authentic environments yield higher levels of openness.

\section{Openness Related to Development of PROFESSIONAL COMPETENCIES}

Progression of developing professional competencies should be seen from a degree program perspective. The content of Table I can serve as guide in designing this progression. The level of openness is an essential component in such an effort, since just about all of the competencies require an ability to deal with openness. The ability to deal with openness is however a complex endeavour that should be progressively developed. 
The framework for openness in education provides a toolbox for reasoning about openness with regard to educational interventions aimed at development of some aspect(s) of professional competencies, e.g. from those listed in Table I. All categories should be considered when designing an educational intervention and progression can be build into a degree program by specifying aspects of the factors identified under each category to be addressed. The level of openness for the selected factors is essential in this specification.

A model of professional competence, where a competence is the balanced use of knowledge, attitude, and skill, can also be used to describe progress. That is, the first step could be to cover only one of these components, e.g. theoretical knowledge regarding team work or algorithms. This could be followed by either deepening the coverage of the component or adding components, the latter could be to work in teams and reflect on the process according to theory. The level of openness increases along with increases in realism in the use of the specific competence.

A similar structure for structuring progression is central in the CDIO concept [27], i.e. Conceive, Design, Implement, and Operate. The Conceive, Design, Implement, and Operate form a chain of progression in the CDIO model and is assumed to be clearly stated in course specifications comprising a degree program. Progression of any aspect, or combination of aspects, in the framework can be seen as following that chain. The level of openness can be specified in the CDIO concept.

\section{Openness Related to 21st Century Skills}

We briefly discuss development of two of the subcategories in Table I: Knowledge and Leadership, in relation to the framework of openness in education. They are chosen, since they represent one aspect that is generally considered natural to develop in open project settings, i.e., leadership, and one that often seen as problematic in such settings, i.e., knowledge.

Note that the faculty involvement is a central category in all settings designed to develop professional competencies, with high level of involvement corresponding to low levels of openness and vice versa.

\section{A. Knowledge}

Development of knowledge, a cognitive competence, is a broad area that can be seen as being addressed by every aspect of the framework for openness, although the most central is the Character of problems category. Laying a foundation of basic knowledge is possible, arguably even best, in educational settings with a low level of openness [13]. The more open an educational setting is the less is the control over specific knowledge covered. This does not imply that no knowledge is gained, but rather that it is related to the choices made by students, and potentially meaning that students gain different knowledge. The relevance of the framework for openness in education in the case of progression of knowledge mostly stem from the desired level of control of knowledge offered to students. This is closely related to the issue of learning objectives and assessment, where course specification that include detailed and low level descriptions might severely limit the level of openness.

The model of competence as consisting of a balanced use of knowledge, attitude, and skill imply that knowledge is a component of all other subcategories and terms in Table I. Progression of most of these subcategories and terms typically require educational settings with high levels of openness, and this also includes development of relevant knowledge.

\section{B. Leadership}

Development of leadership, an interpersonal competence, is most directly addressed in the Character of the teams and the Time constraints categories. The openness aspect is of outmost importance in developing a degree program where leadership is addressed. The leadership competence is truly complex and there is a need to develop this ability through progression from structured interventions with low levels of openness to highly complex learning situations with high levels of openness. To fully address the leadership competence all aspects of the character of the teams and the time constraint categories should be included at high levels of openness. The External factors category is also quite relevant for the highly open settings, with for instance having an external stakeholder being an excellent opportunity to develop self-presentation skills.

\section{CONCLUSION}

Regarding openness as aspects adding to the complexity of educational projects, we have presented a framework that provides a structured view of challenges related to openness that students can encounter. The framework is suitable to serve as an aid in planning for systematic progression in project work over the course of a degree program. We have identified progression in project work and in development of professional competencies as often lacking and thereby posing a major obstacle for fully exploiting the potentials of using projects as an educational tool.

What is of essential importance is to understand that openness is a complex concept and that a graduate should be fully confident with handling true openness in order to be professionally competent. The framework should be complemented by adding a toolbox of assessment methods related to the aspects relevant for assessing.

\section{REFERENCES}

[1] Organisation for Economic Co-operation and Development (OECD), "The definition and selection of key competencies: Executive summary," 2005. [Online]. Available: http://www.oecd.org/pisa/35070367.pdf

[2] W. Aspray, F. Mayadas, and M. Y. Vardi, "Globalization and offshoring of software," in Innovation Imperative: National Innovation Strategies in the Global Economy. Edward Elgar Publishing, 2009, ch. 3, p. 24

[3] J. W. Pellegrino and M. L. Hilton, Eds., Education for life and work: Developing transferable knowledge and skills in the 21st century. National Academies Press, 2013.

[4] S. Nordberg, "Framtidens ingenjör-det här behöver du," Ingenjörskarriär, 2013. [Online]. Available: http://www.ingenjorskarriar.se/din_utveckling/article3786583.ece

[5] IEEE Computer Society, "Software engineering competency model (SWECOM) version 1.0," 2014. [Online]. Available: http://www.computer.org/portal/web/pab/SWECOM 
[6] E. P. Douglas, M. Koro-Ljungberg, N. J. McNeill, Z. T. Malcolm, and D. J. Therriault, "Moving beyond formulas and fixations: solving open-ended engineering problems," European Journal of Engineering Education, vol. 37, no. 6, pp. 627-651, 2012.

[7] M. K. Larusdottir, M. Daniels, and R. McDermott, "Quality assurance using international curricula and employer feedback." in Proceedings of the 17th Australasian Computing Education Conference (ACE 2015). Australian Computer Society, Inc., 2015, pp. 19-27.

[8] E. F. Barkley, K. P. Cross, and C. H. Major, Collaborative learning techniques: A handbook for college faculty. John Wiley \& Sons, 2014.

[9] J. Sibley and P. Ostafichuk, Getting started with team-based learning. Stylus Publishing, LLC, 2015.

[10] A. Kolmos, "Problem-based and project-based learning," University science and mathematics education in transition, pp. 261-280, 2009.

[11] A. Hauer and M. Daniels, "A learning theory perspective on running open ended group projects (oegps)," in Proceedings of the tenth conference on Australasian computing education-Volume 78 . Australian Computer Society, Inc., 2008, pp. 85-91.

[12] E. B. Durán and A. Amandi, "Personalised collaborative skills for student models," Interactive Learning Environments, vol. 19, no. 2, pp. 143-162, 2011.

[13] P. A. Kirschner, J. Sweller, and R. E. Clark, "Why minimal guidance during instruction does not work: An analysis of the failure of constructivist, discovery, problem-based, experiential, and inquiry-based teaching," Educational psychologist, vol. 41, no. 2, pp. 75-86, 2006.

[14] M. Shaw and J. E. Tomayko, Models for undergraduate project courses in software engineering. Berlin, Heidelberg: Springer Berlin Heidelberg, 1991, pp. 33-71. [Online]. Available: http://dx.doi.org/10.1007/BFb0024284

[15] P. J. Knoke, Medium size project model: Variations on a theme. Berlin, Heidelberg: Springer Berlin Heidelberg, 1991, pp. 3-24. [Online]. Available: http://dx.doi.org/10.1007/BFb0024282

[16] S. Fincher, M. Petre, and M. Clark, Eds., Computer Science Project Work: Principles and Pragmatics. London, UK: Springer-Verlag, 2001.

[17] T. Clear, M. Goldweber, F. H. Young, P. M. Leidig, and K. Scott, "Resources for instructors of capstone courses in computing," SIGCSE
Bull., vol. 33, no. 4, pp. 93-113, Dec. 2001. [Online]. Available: http://doi.acm.org/10.1145/572139.572179

[18] K. Bothe, "Reverse engineering: the challenge of large-scale real-world educational projects," in Proceedings of the 14th Conference on Software Engineering Education and Training, 2001. IEEE, 2001, pp. 115-126.

[19] J. E. Burge and G. C. Gannod, "Dimensions for categorizing capstone projects," in 22nd Conference on Software Engineering Education and Training, 2009. CSEET'09. IEEE, 2009, pp. 166-173.

[20] R. H. Todd, S. P. Magleby, C. D. Sorensen, B. R. Swan, and D. K Anthony, "A survey of capstone engineering courses in north america," Journal of Engineering Education, vol. 84, no. 2, pp. 165-174, 1995.

[21] D. Richards, "Designing project-based courses with a focus on group formation and assessment," ACM Transactions on Computing Education (TOCE), vol. 9, no. 1, p. 2, 2009.

[22] A. Pears and M. Daniels, "Developing global teamwork skills: The runestone project," in Education Engineering (EDUCON), 2010 IEEE. IEEE, 2010, pp. 1051-1056.

[23] J. Heikkinen and V. Isomöttönen, "Learning mechanisms in multidisciplinary teamwork with real customers and open-ended problems," European Journal of Engineering Education, vol. 40, no. 6, pp. 653670,2015

[24] A. Hauer and M. Daniels, "A learning theory perspective on running open ended group projects (OEGPs)," in Proceedings of the tenth conference on Australasian computing education-Volume 78 (ACE '08), vol. 78. Darlinghurst, Australia: Australian Computer Society, Inc., 2008, pp. 85-91.

[25] O. N. Kwon, J. H. Park, and J. S. Park, "Cultivating divergent thinking in mathematics through an open-ended approach," Asia Pacific Education Review, vol. 7, no. 1, pp. 51-61, 2006.

[26] M. Apiola, M. Lattu, and T. A. Pasanen, "Creativity-supporting learning environment-CSLE," ACM Transactions on Computing Education (TOCE), vol. 12, no. 3, pp. 11:1-11:25, Jul. 2012. [Online]. Available: http://doi.acm.org/10.1145/2275597.2275600

[27] E. F. Crawley, J. Malmqvist, S. Östlund, D. R. Brodeur, and K. Edström, Rethinking engineering education: The CDIO approach. Springer International Publishing, 2014. 